\title{
Predicting Appraised Value of Parcels of Harris County, Texas Using LEED Criteria for Public Transportation Access
}

\author{
Hee Su Han ${ }^{1}$, Boo-Young Kim², Young Jun Park ${ }^{3}$ and Kiyoung Son*4 \\ ${ }^{1}$ Ph.D. Student, Department of Urban Planning \& Real Estate, Dankook University, Republic of Korea \\ ${ }^{2}$ M.S. Student, School of Architecture, University of Ulsan, Republic of Korea \\ ${ }^{3}$ Associate Professor, Department of Civil \& Environmental Engineering, Korea Military Academy, Republic of Korea \\ ${ }^{4}$ Assistant Professor, School of Architecture, University of Ulsan, Republic of Korea
}

\begin{abstract}
The objective of this study is to determine if the appraised unit value $(\$ / \mathrm{sf})$ of unimproved land parcels in Houston, Texas could be predicted by a regression equation containing a group of independent variables that represent LEED transportation access criteria and the area of a land parcel. The independent variables, number of bus stops, number of rail stops and parcel area, were all found to contribute significantly to the independent variable, appraised unit value of a parcel. The observational unit was properties in Houston, Texas that were unimproved (had zero improvement value). Findings suggest that the acceptance criteria for the LEED green building rating system regarding public transportation access have a significant influence on the appraised value in dollars per square foot of the subject properties. Based on the sample median lot size of 5,300 square feet, the predicted lot value increases dramatically in proportion to the number of qualifying light rail stations and decreases marginally in proportion to the number of qualifying bus stops. Since the regression model and each independent variable were all significant at $\mathrm{p}<0.05$ and the adjusted $\mathrm{R}$-square was near 0.50 , the study objective was deemed to have been answered in the affirmative.
\end{abstract}

Keywords: sustainable development; LEED; public transportation access; sustainable site; regression analysis

\section{Introduction}

Awareness of sustainability and the environment has led to the emergence of various voluntary standards for buildings such as LEED (USA). These standards claim to be market driven and serve as environmental building assessment methods. For these approaches to be viable as well as successful, it is essential to find out if the value of green projects incorporates environmental costs and benefits. "Green buildings" have gained popularity in some sectors of the economy in response to pricing signals. Little empirical evidence is available to support the idea that commercial real estate prices incorporate sustainability characteristics despite the financial and environmental benefits of building sustainability. Unfortunately, very few studies have attempted to gauge the price effects of green building ratings (Fuerst and McAllister 2011; Lee and Yeom 2012).

*Contact Author: Kiyoung Son, Assistant Professor,

School of Architecture, University of Ulsan, 93 Daehakro,

Ulsan, 680-749, Republic of Korea

Tel: +82-52-259-2788 Fax: +82-52-259-1690

E-mail: sky9852111@ulsan.ac.kr

(Received April 2, 2014 ; accepted October 31, 2014)
The aim of this study is to predict the appraised values (in dollars per square foot) of unimproved parcels in Harris County, Texas, based on the LEED sustainable rating for Public Transportation Access. The population of interest was parcels which were within one mile outside of Beltway 8 , which encircles Texas. Parcels, randomly selected, were unimproved. As specified by the Harris County Appraisal District, these parcels had zero improvement value. Each parcel served as an observational unit for data collection and analysis. The theme of this research was quantitative and the data gathered was analyzed using appropriate statistical tools. If the suggested model indicates a significant relationship between unit value (dollars per square foot) of land and LEED rating, property market value will be consistent with the LEED public transportation access criteria. Knowledge of potentially increased property values may encourage project developers to site their projects where public transportation is accessible.

\section{Literature Review}

\subsection{Sustainable Land Development}

Various perspectives have been contemplated to answer questions like "Why do organizations adopt voluntary, environmental standards?" and "What is the 
societal value of such standards?" Organizations might be motivated to adopt innovations, including voluntary standards because they want to be recognized for their commitment to environmental issues in their industry (Lee and Yeom 2009). They might want to communicate something about their practices to the outside world, including regulators, customers and the public. On the other hand, adoption may be driven by the pursuit of elemental benefits, meaning that the organization anticipates actual economic and/or environmental benefits that are a direct result of the standards, regardless of perceptions of the outside world (Corbett and Muthulingam 2007).

USGBC, through its publication LEED for New Construction Version 3.0, presents sustainable site guidelines and encourages using these metrics to make decisions regarding sustainable land development (USGBC 2009). As mentioned earlier, this rating system helps to make decisions regarding land development/restoration projects in such a way that the local ecosystem is preserved. Sustainability of land development/restoration projects optimizes economic value while preserving the environment (USGBC 2011). Unfortunately, there are very few studies which attempt to understand the economic worth of this voluntary rating system. This paper focuses on identifying the relationship between the LEED sustainability rating (Public Transportation Access) and the economic worth of the land. If there is no meaningful relationship between these variables, then it may be difficult to justify the motivation of organizations to adopt these voluntary standards. Moreover, it will be difficult to encourage sustainable land development/restoration projects for economic reasons.

Sales price information is difficult to gather. Also, infrequency of sales makes the parcels incomparable on a value basis. This infrequency makes it difficult to know the amount at which any given land will transact at any given time (Rappaport 2007). Hence, appraised value of parcels appeared to be the best alternative to make meaningful comparisons. "No two houses are the same. The specific combination of attributes, both locational and physical, associated with any building determines that building's quality" (Choi and Cho 2014). Heterogeneity among buildings makes comparisons difficult if not impossible.

In addition, the appraised land value can be affected by economic conditions such as inflation (or deflation) over time. To effectively control this factor, the studied data were limited to parcels for "unimproved" lands only. The real property values consist of land plus any improvements attached to the land (Son et al. 2013). Externalities like the economic condition may affect the value of improved lands. As this study focuses on the appraised value of unimproved lands, changes in the value of lands associated with time-variability can be minimized. Therefore, for this study, only unimproved land with zero improvement value was considered.

Houston, Texas is ranked as the fourth most populous city in the United States (City of Houston, 2009). Since 1999, Houston has alternated its position with Los Angeles for being the most polluted city in the United States (Wilson 2007). Along with pollution caused by petrochemical and power plants, Houston faces severe pollution caused by automobiles. The prime reason for the pollution is congested highways, which are due to enormous population-growth in the last decade. According to U.S Census Bureau (2000) statistics, the population of Houston has increased by $19.7 \%$ from 1990 to 2000 . People are forced to move further out into the surrounding suburbs in search of affordable housing. As a result, the city's population is facing increasingly longer commutes between home, work and leisure. Houston is now spread over a significant area. This poses a challenge for authorities, who are responsible for implementing measures to reduce pollution.

According to the U.S. Census Bureau (2000) data, mean travel time to work is 27 minutes. This data also shows that $77.8 \%$ drove alone and $12.7 \%$ carpooled with private automobiles. This has put local government under constant pressure to keep the infrastructure, such as highways, roads, and public transit, operating well. New highways are under construction and more road lanes are added to existing highways to meet the current needs of the public and to provide adequate capacity for the future. U.S Census data suggests that people prefer private automobiles to the existing mass transit system. This might be because existing transit facilities are somewhat inefficient or that they have limited connectivity. Local authorities in Houston are considering efficient mass transit systems to reduce pollution caused by automobile use. LEED encourages developers to select sites that have convenient access to mass transportation networks (USGBC 2009).

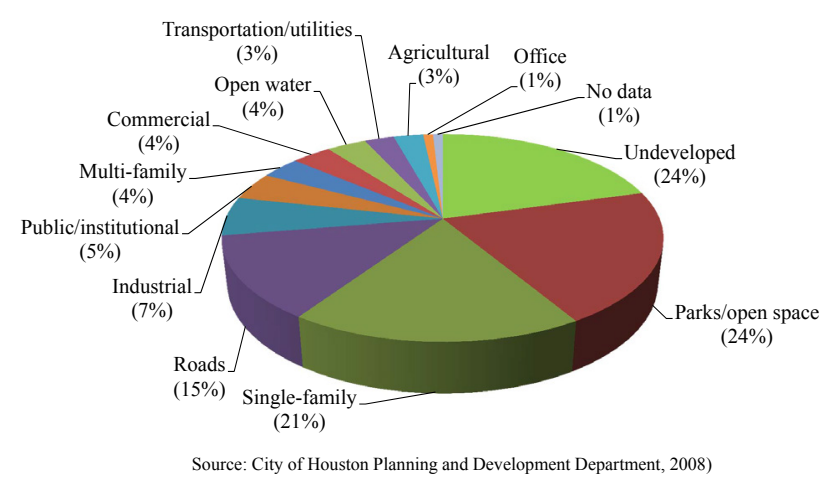

Fig.1. Land Use Distribution in the City of Houston

Houston has the largest area, 618 square miles, of all major US cities. Houston is the largest city in Texas in terms of population, size and number of persons per square mile. Between 1990 and 2000, Houston had a 
very small (1.2\%) increase in owner occupied units. Also, the housing value increased by $1.05 \%$ from 1990 to 2000 (City of Houston Planning and Development Department 2008). The pie-chart (see Fig.1.) shows land use distribution in the City of Houston. In 2000, vacant and undeveloped land accounted for $24 \%$ (i.e. 91,370 acres) of the total land use in the city. This largest single land use classification is followed by single-family residential use.

Almost 1/3 of the City's vacant land is located south of Loop 610, accounting for 29,008 acres in total. Vacant land inside Loop 610 is comprised of small parcels distributed with mixed uses. Vacant parcels located towards the city boundaries tend to be large, causing discontinuities in the patterns of urbanization (City of Houston Planning and Development Department 2008). This land use pattern is important to consider since this research study included only vacant parcels.

\subsection{LEED for New Construction}

In 2000, the U.S Green Building Council (USGBC) released a rating system called the Leadership in Energy and Environmental Design (LEED) for New Construction (LEED-NC). This rating system along with focusing on the building operational and maintenance issues, addresses the different project development/delivery processes that exist in the US building design and construction market (USGBC 2009).

This LEED-NC addresses the environmental impacts of site and materials selection, demolition, and construction. Since its launch in 2000, over 4,000 building projects have certified for LEED-NC in the U.S. (USGBC 2011). The primary goal of LEED$\mathrm{NC}$ is to promote healthful, durable, affordable, and environmentally sound practices in building design and construction (USGBC 2009). LEED-NC levels are awarded according to the following:

1) Certified: $40-49$ credits

2) Silver 50-59 credits

3) Gold 60-79 credits

4) Platinum: 80 points and above

LEED-NC addresses seven categories such as Sustainable sites, water efficiency, energy and atmosphere, materials and resources, indoor environmental quality, innovation in design, and regional priority (Joshi 2009). Among them, in Sustainable Sites Credits (SSC), there are eight credits such as a) site selection, b) community connectivity, c) brownfield redevelopment, d) alternative transportation, e) site development, f) storm water design, g) heat island effect, and h) light pollution reduction. This SSC consists of 26 credits out of 110 . Among SSC, this study has focused on credit 4.1: Public Transportation Access (PTA). The credit has the following aspects:

1) Locate project within $1 / 2$ mile walking distance (measured from a main building entrance) of an existing or planned and funded- commuter light rail, light rail or subway station.

2) Locate project within $1 / 4$ mile walking distance (measured from a main building entrance) of one or more stops for two or more public bus lines usable by building occupants.

\section{Hypothesis and Data Collection \\ 3.1 Hypothesis}

The linear regression model tested the predictability of the unit value of a parcel using the area of the parcel, number of bus stops and number of rail stations that met LEED criteria for that parcel. The model was used only for those parcels that qualified for LEED credit. The model had one dependent variable; appraised value/square foot of a parcel. The following were independent variables which were considered as predictors of the dependent variable:

- Independent Variable 1: Number of bus stops which met the LEED criteria

- Independent Variable 2: Number of rail stations which met the LEED criteria

- Independent Variable 3: Area of parcel, measured in square feet

Here, the hypothesis to be tested was that this model was statistically significant and was capable of predicting the appraised value per square foot of the parcel using the independent variables.

Appraised Value/square foot of a parcel $=\beta_{0}+\beta_{1}$ (Number of bus stops for a given parcel that met LEED criteria) $+\beta_{2}$ (Number of rail stations for a given parcel that met LEED criteria) $+\beta_{3}$ (Area of parcel) $+\varepsilon$.

$\cdot \beta_{0}=$ intercept, appraised value per square foot of a parcel when neither bus stops nor rail stations met the LEED criteria

$\cdot \beta_{1}=$ partial slope for number of bus stops or expected change in appraised value per square foot of a parcel when one more bus stop which met the LEED criteria was added to the parcel while controlling other independent variables

$\cdot \beta_{2}=$ partial slope for number of rail stations or expected change in appraised value per square foot of a parcel when one more rail station which met the LEED criteria was added to the parcel while controlling other independent variables

$\cdot \beta_{3}=$ partial slope for area of parcel

$\cdot \varepsilon=$ error

This model was derived from a sample of 150 parcels that included the number of bus stops and rail stations which were within the qualifying LEED distances.

\subsection{Population of Interest}

As shown in Fig.2.(a), the study parcels were within one mile outside of Beltway 8 encircling and within 
the city limits of Houston, Texas. The population of interest contained only parcels which were unimproved. According to the Harris County Appraisal Data, parcels with zero improvement value were considered unimproved. All these parcels formed the population of interest for this research.

\subsection{Sample Selection}

From the population of unimproved parcels, all parcels that met LEED criteria for public transportation were listed. A random selection of 150 parcels, which qualified for LEED rating for Public Transportation Access, was made. These parcels formed the treatment group.

Likewise, 150 paired parcels, which did not qualify for LEED rating, and were located in the vicinity of each parcel of the treatment group, were selected. These parcels were a part of the control group for analysis purposes. Therefore, a total of 150 pairs of properties were selected for this study. Half of them qualified for the LEED Public Transportation Access rating and the other half did not.

\section{Collection Method \\ 4.1 Population Mapping}

The parcels in this study lie within one mile outside of Beltway 8, which encircles Houston, Texas. This population will be represented on a map using GIS. In addition, appraised values of all the parcels selected in the previous step were recorded using Harris County Appraisal District data. To collect this information, a 13-digit parcel ID was used and the appraised value was retrieved. All parcels which had zero improvement value were then listed. This list consisted of all parcels with zero improvement value. The population so obtained was considered for this research.

\subsection{Selection of Treatment Group}

A GIS file containing all population parcels was then projected on the Arc Map. Transportation maps of bus stops and light rail stations were obtained from the Houston-Galveston Area Council (HGAC 2009). These maps were then layered over the population map. This defined the location of all bus stops and light rail stations with respect to the population considered. Fig.2.(b) illustrates this procedure graphically.

In order to select the treatment group, the buffer function of GIS was used. The parcels which were within a quarter mile (measured from the centroid of the parcel) of bus stops and/or within half a mile of light rail stations were selected. Fig.2.(c) and (d) are a pictorial presentation of this procedure.

All these selected parcels met LEED criteria for public transportation. While collecting data, it was found that a few of the parcels which qualified for LEED credit had both bus stop and light rail stations within qualifying distances. The rest of the parcels either met bus stop distance criteria or light rail distance criteria. So, three groups of LEED qualifying parcels were formed for the analysis.

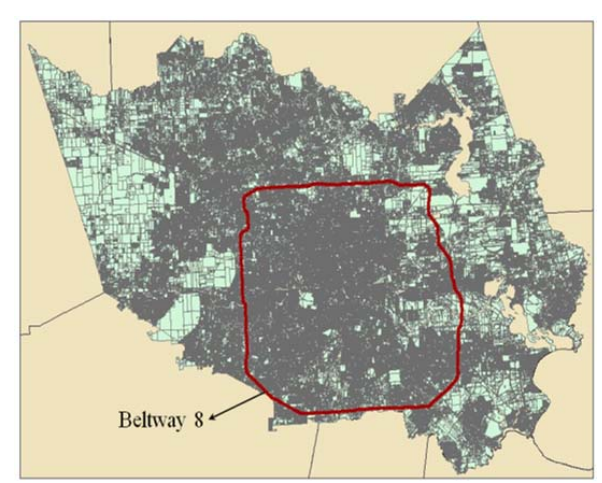

(a)

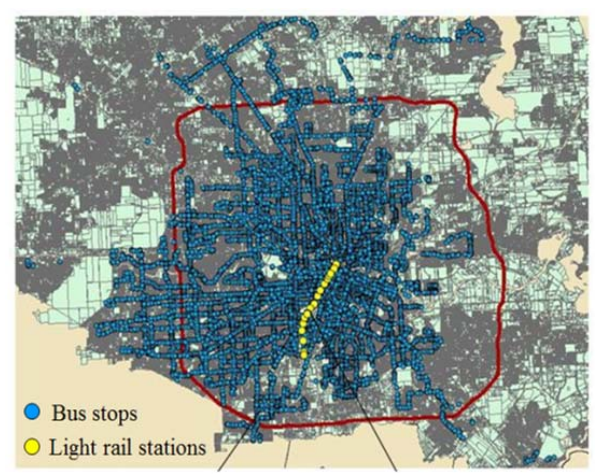

(b)

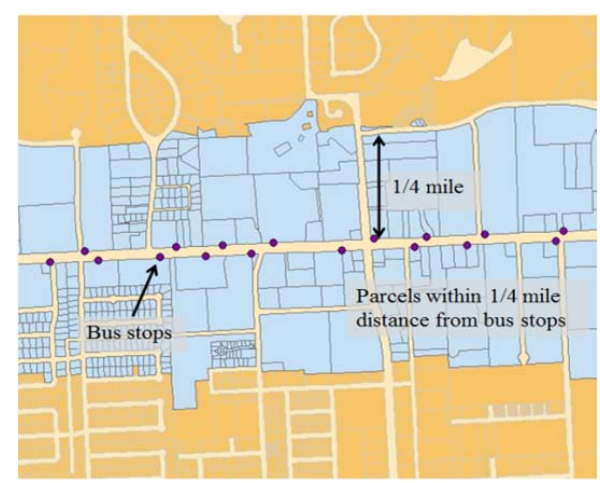

(c)

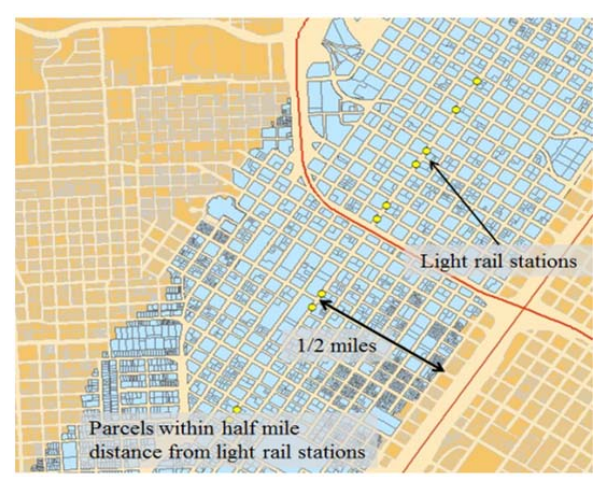

(d)

Fig.2. Mapping Process

The first group consisted of all parcels which had both bus stops and light rail stations within qualifying distances. All the parcels in the second group were located within a quarter mile of a bus stop. All parcels in the third group were located within half a mile 
of a light rail station. In this study, 50 parcels were randomly selected from each of the three groups. Thus, a total of 150 parcels were randomly selected. This formed the sample of interest for this research.

\subsection{Area of Parcels and Number Data}

The area of all 150 parcels was obtained from Harris County Appraisal District public data which contained 13-digit parcel IDs. Also, using the centroids of parcels as reference points, the distance to transit points was calculated. An Excel matrix model was created using the spherical law of cosines. With the help of the matrix model, the number of bus stops and/or light rail stations that met LEED criteria for each parcel was calculated.

\section{Data Analysis}

\subsection{Descriptive Statistics}

According to Table 1., the dependent variable unit value, $(\$ / \mathrm{SF})$, had a mean value of about $\$ 27.25$ per square foot and a median value of $\$ 17.00$ per square foot. The lowest unit value was about $\$ 0.05$ per square foot and the highest was $\$ 175.00$ per square foot. There were a few parcels that had a very high unit value per square foot in the sample. The independent variable Area, (SF), had a mean of about 13,536 square feet and a median of 5,300 square feet. The lowest value was 41 square feet and the highest value was 458,251 square feet. Few of the parcels had a very high value for the land area associated with them. The area considered for this set of results was $0.51 \%$ of the total undeveloped land area of the City of Houston. The appraised value, (\$), had a mean value of about $\$ 311,638$ and a median of $\$ 91,590$. It ranged from $\$ 62$ to $\$ 13,568,900$. Parcels with these lowest and highest appraised values met all the criteria to be in the population. These parcels had zero improvement value and qualified for LEED public transportation access credit.

Table 1. Descriptive Statistics for Unit Value (\$/SF)

\begin{tabular}{crrr}
\hline Contents & Unit Value & \multicolumn{1}{c}{ Area } & Appraised Value \\
\hline Mean & 27.24 & $13,535.81$ & $311,637.61$ \\
Minimum & 0.05 & 41 & 62 \\
Maximum & 175 & 458,251 & $13,568,900$ \\
Standard & 27.56 & $44,894.53$ & 1.15 \\
deviation & & & 10.34 \\
Skewness & 2.17 & 8.07 & 117.39 \\
Kurtosis & 7.72 & 72.24 & \\
\hline
\end{tabular}

\subsection{Diagnostics}

Since the sample size for this model was more than 50 , the Kolmogorov Smirnov significance value was used for testing the normality of residuals. $p=0.000<$ 0.05 (alpha level) for the Kolmogorov-Smirnov test of normality proved that residuals were not normal (see Fig.3.). Hence, the normality test failed because of the residuals from the initial regression when the original values for the dependent variable were used. Also, a histogram of standardized residuals showed a nonnormal distribution of residuals.

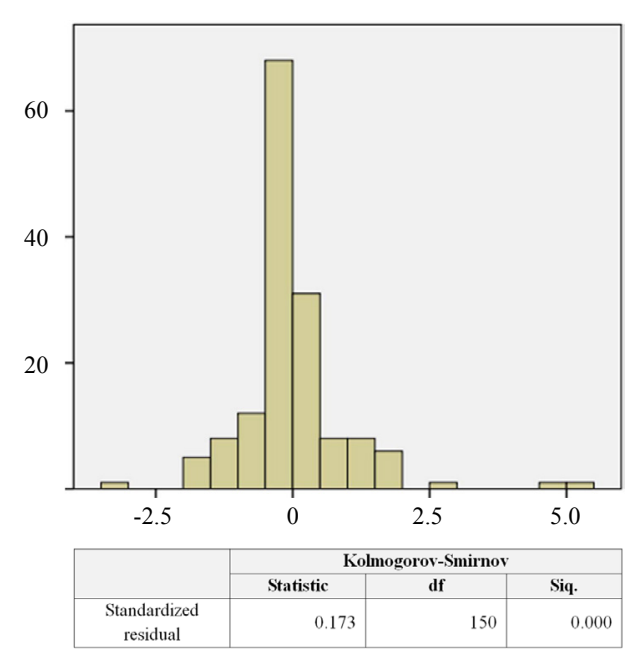

Fig.3. Test of Normality

\subsection{Transformation of Dependent Variable}

Since formal assumptions to carry out regression were not met, the dependent variable (unit value) was transformed. A Box-Cox transformation was used to find the appropriate transformation. BoxCox suggested two possible transformations for the dependent variable. For analysis purposes, the following transformation was used.

$$
\text { Transformed Unit Value }=(\text { Original Unit Value })^{0.3}
$$

\subsection{Regression Analysis}

The following model was considered after the transformation:

Transformed Unit Value $=\beta_{0}+\beta_{1}$ (Number of bus stops $)+\beta_{2}$ (Number of light rail stations) $+\beta_{3}$ (Area) $+\varepsilon$

Table 2. shows the ANOVA table of the transformed model. From the p-value obtained from the analysis, a statistically significant linear relationship existed between dependent and independent variables. A transformed unit value for the parcels was found to be linearly related to the area, number of bus stops and number of rail stations. Because this relationship existed, the multiple regression correlation value was also significant.

Table 2. ANOVA and Adjusted R Square

\begin{tabular}{cccccc}
\hline Model & $\begin{array}{l}\text { Sum of } \\
\text { squares }\end{array}$ & df & $\begin{array}{c}\text { Mean } \\
\text { square }\end{array}$ & F & Siq. \\
\hline Regression & 52.20 & 3 & 17.40 & 49.25 & 0.00 \\
Residual & 51.58 & 146 & 0.35 & & \\
$\quad$ Total & 103.78 & 149 & & & \\
\hline a. Predictors: (Constant), Area, Number of rail stations, & \\
& Number of bus stops \\
b. Dependent Variable: Transformed Unit Value &
\end{tabular}

Adjusted R- square for this model was 0.493 . That is $49.3 \%$ of the variability in the transformed unit value of parcels could be explained by the independent 
variables. Even though all independent variables were found to be significant predictors, they were not as powerful as one might hope. About half, 49.3\%, of the variability in the transformed unit value of parcels could be explained by these independent variables, whereas $50.7 \%$ of the variability was due to other unknown factors not considered in this research.

Table 3. Coefficients

\begin{tabular}{ccccc}
\hline \multirow{2}{*}{ Model } & Unstandardized Coefficients & t & Siq. \\
& $\mathrm{B}$ & Std. Error & & \\
\hline (Constant) & 1.873 & 0.068 & 27.422 & 0.000 \\
NumBus & -0.015 & 0.005 & -3.004 & 0.003 \\
NumRail & 0.426 & 0.043 & 9.980 & 0.000 \\
Area & $-2.522 \mathrm{E}-6$ & 0.000 & -2.301 & 0.023 \\
\hline
\end{tabular}

Parameter estimates showed that all three independent variables, number of bus stops, number of rail stations and area, were significant predictors of transformed unit value of a parcel. The number of rail stations meeting LEED criteria for a given parcel had the greatest effect on the transformed unit value as compared to other independent variables in the model.

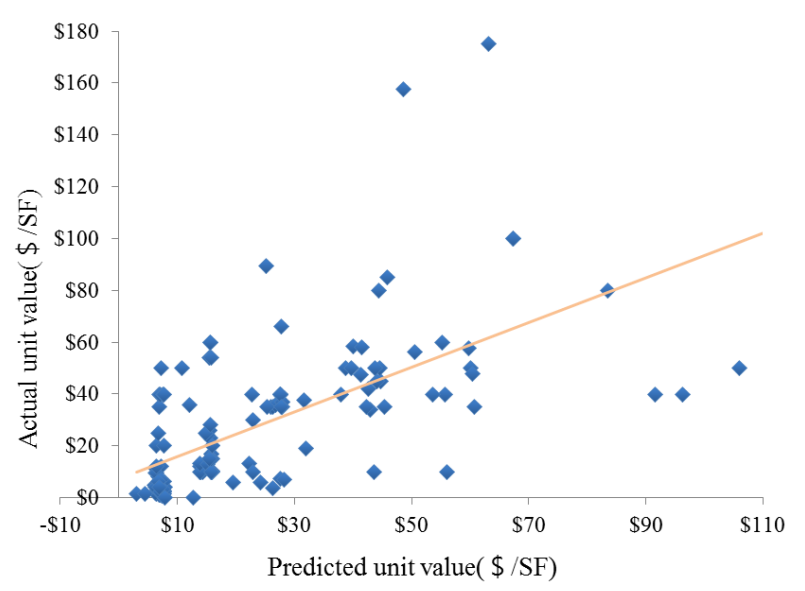

Fig.4. Actual Unit Value Vs. Predicted Unit Value

A predictive equation was obtained for the transformed unit value and un-transformed unit value. This model used the best estimates of the population parameters. Also, actual unit value and predicted unit value were compared (see Fig.4.).

Predicted Transformed Unit value $=1.873-0.015$ (NumBus) + 0.426 (NumRail) - 0.000002522 (area)

Predicted Un-Transformed Unit value $=1.873$ -0.015 (NumBus) + 0.426 (NumRail) -0.000002522 (area) ${ }^{(1 / 0.3)}$

\subsection{Discussion}

The multiple regression analysis showed that both number of bus stops and area were significant predictors of the transformed unit value. For this model, the ANOVA test $\mathrm{p}$ value was 0.000 . Therefore, the research hypothesis, which stated that the model was appropriate and that number of bus stops, number of light rail stations and area were significant predictors of the transformed unit value of a parcel, was accepted. This model demonstrates a significant relationship between the transformed unit value of parcels and the measurements required to earn LEED credit. Independent variables used in this model, namely the number of bus stops meeting LEED criteria, the number of light rail stations meeting LEED criteria and area, together accounted for $49.3 \%$ of the variability in the transformed unit value of the parcels. These variables emerged as significant predictors but were not very powerful since $50.7 \%$ of the variation in the transformed unit value was explained by other factors which were not considered in this research.

Therefore, to find best-fit models for predicting the appraised unit value of parcels in Harris County, it is meaningful to use other possible variables such as other LEED criteria, household income, the level of education, etc.

\section{Conclusions}

For the model, predictability of transformed unit value of a parcel meeting LEED criteria using the number of transit points, i.e. bus stops and light rail stations (located within the qualifying LEED distances) and area was calculated. According to the results, an increase in the number of light rail stations led to an increase in the transformed unit value of a parcel. The number of bus stops which met LEED criteria for a given parcel had a completely opposite effect.

Based on the sample median lot size of 5,300 square feet, the predicted lot value increases dramatically in proportion to the number of qualifying light rail stations and decreases marginally in proportion to the number of qualifying bus stops. This effect can be clearly seen in Table 4. for a lot with an area held constant at the sample median of 5,300 square feet. As the number of rail and bus stops are varied over a range of zero to four bus stops and zero to two rail stops, the predicted value of the parcel is calculated. In every case, the value of the median lot increases when the number of rail stops increases and decreases when the number of bus stops increases. For example the predicted value for a median sized lot of 5,300 square feet with no bus stop or rail stop is $\$ 41,915$. The same size lot with no bus stops and one rail stop has a predicted value of $\$ 83,361$. The lot value is almost doubled by adding access to a qualified rail stop. Therefore, it can be concluded that the number of rail stops has significant effect on the value of parcels in Harris County.

For the same lot size with a value of $\$ 41,915$ with access to neither a bus nor rail stop, the difference is noticeable relative to the addition of a bus stop rather than a rail stop. With zero rail stops and one bus stop, the predicted value is $\$ 40,798$. This is a drop in 
Table 4. Bus and Rail Stop Effect on Value

\begin{tabular}{ccc}
\hline Bus Stops & Rail Stops & Predicted Value \\
\hline 0.00 & 0.00 & $\$ 41,915$ \\
1.00 & 0.00 & $\$ 40,798$ \\
2.00 & 0.00 & $\$ 39,703$ \\
3.00 & 0.00 & $\$ 38,628$ \\
4.00 & 0.00 & $\$ 37,574$ \\
0.00 & 1.00 & $\$ 83,361$ \\
1.00 & 1.00 & $\$ 81,552$ \\
2.00 & 1.00 & $\$ 79,770$ \\
3.00 & 1.00 & $\$ 78,015$ \\
4.00 & 1.00 & $\$ 76,288$ \\
0.00 & 2.00 & $\$ 147,360$ \\
1.00 & 2.00 & $\$ 144,660$ \\
2.00 & 2.00 & $\$ 141,995$ \\
3.00 & 2.00 & $\$ 139,365$ \\
4.00 & 2.00 & $\$ 136,769$ \\
\hline
\end{tabular}

predicted value of over $\$ 1,100$ due to adding one bus stop. The difference between adding one bus stop and adding one rail stop is $\$ 42,563$.

This pattern may be particular to Houston because the light rail stations are concentrated more towards the center of the city, i.e. downtown area, rather than being distributed all over the city. On the other hand, bus stops are located all over the city. Area was found to be a significant predictor of the transformed unit value. As the plot area increased, the transformed unit value of a parcel went down.

The model suggested that selection characteristics of the LEED green building rating system for public transportation access influences the appraised value of properties. This finding further implies that the market indirectly considers the economic effect of the LEED rating system even though this assessment method does not explicitly include financial aspects in the evaluation framework. This research suggests that a sustainable feature of a site may be related to the economic worth of a related land development project. This could encourage new sustainable land development projects.

This is the first investigation of its kind. Future studies will need to identify other factors that could explain more of the variation in the unit value of parcels. Also, the findings of this research were based on the City of Houston. Future studies could focus on other cities.

\section{Acknowledgement}

This work was supported by the 2014 Research Fund of University of Ulsan.

\section{References}

1) Fuerst, F., and McAllister, P. (2011). "Green Noise or Green Value? Measuring the Effects of Environmental Certification on Office Property Values." Real Estate Economics, 39(1), pp.45-69.

2) Lee, K. and Yeom, D. (2012) Comparative research of residents' satisfaction level in KGBCC-Certified apartments in Korea, Journal of Asian Architecture and Building Engineering, 11(1), pp.55-62.
3) Lee, K. and Yeom, D. (2009) Comparative Research of Residents' Satisfaction Level between Green Building-Certified Apartment Complexes and General Apartment Complexes in Korea, Journal of Asian Architecture and Building Engineering, 8(2), pp.423-430.

4) Corbett, C. J., and Muthulingam, S. (2007). "Adoption of Voluntary Environmental Standards: The Role of Signaling and Intrinsic Benefits in the Diffusion of the LEED Green Building Standards." UCLA Institute of the Environment and Sustainability. Retrieved April 8, 2013. http://www.environment.ucla.edu/ccep/ research/article.asp?parentid $=752$

5) U.S Green Building Council (USGBC). (2009). "LEED-NC for New Construction Reference Guide Version 3.0." Report. U.S Green Building Council (USGBC). Washington D.C.

6) U.S. Green Building Council (USGBC). (2011). "LEED Projects \& Case Studies." USGBC, Retrieved June 3, 2013. http://www. usgbc.org/LEED/Project/

7) Rappaport, j. (2007). "Comparing Aggregate Housing Price Measures." Business Economics, 42(4), pp.55-65.

8) Choi, J. and Cho, T. (2014) Comparing perception concerning the importance of apartment complex components between consumers and housing providers, Journal of Asian Architecture and Building Engineering. 13(1), pp.109-116.

9) Son, K., Lee, S., Lim, C. and Kim, S. (2013) Economic Analysis of Korea Green Building Certification System in the Capital Area Using House-Values Index, Journal of Asian Architecture and Building Engineering. 13(2), pp.475-481.

10) City of Houston. (2009). "Houston Facts and Figures." City of Houston, Retrieved February 4, 2013. http://www.houstontx.gov/ abouthouston/houstonfacts.html

11) Wilson, J. (2007). "Getting the Big Picture on Houston's Air Pollution." National Aeronautics and Space Administration. Retrieved March 3, 2013. http:/www.nasa.gov/vision/earth/every daylife/archives/HP_ILP_Feature_03.html

12) U.S. Census Bureau. (2000). "United States Census 2000." U.S. Department of Commerce. Retrieved February 8, 2013. http:// www.census.gov/main/www/cen2000.html

13) City of Houston Planning and Development Department. (2008). "Houston Land Use and Demographic Profile." City of Houston eGovernment Center. Retrieved January 13, 2013. http://www. houstontx.gov/planning/planning_studies/ludem.html

14) Joshi B. (2009) Prediction of unit value of unimproved parcels of Harris County, Master's thesis, Texas A\&M University, College Station, TX, USA.

15) Houston-Galveston Area Council. (2009). "Regional Data \& GIS Services, Houston-Galveston Area Council." Retrieved July 17, 2013. http://www.h-gac.com/rds/gis/clearinghouse/default.asp 